\title{
TURKISH LIRA EXCHANGE RATE FORECASTING USING TIME SERIES MODELS
}

\author{
Marwan Abdul Hameed Ashour ${ }^{1}$ and Iman A.H. Al-Dahhan ${ }^{2^{\star}}$ \\ ${ }^{1}$ Prof. Dr., University of Baghdad, Iraq, dr_marwan2012 @yahoo.com \\ ${ }^{2}$ Assist. Prof. Dr., University of Baghdad, Iraq, emanaldahhan@gmail.com \\ ${ }^{*}$ Corresponding author
}

\begin{abstract}
Financial markets in any country in the world are one of the most important pillars of the economy. The global financial crisis and the current economic and political situation have impacted the regional and international financial markets. To deal with such financial crises in the business markets, a model is essential to describe and address these phenomena which consider variations over time and characterize a suitable and effective model. The aim of this research is to construct a mathematical model for the time series of the Turkish lira compared to the US Dollar by the ARIMA model and to predict the next period ,and to measure the accuracy and efficiency of the model of prediction adopted using statistical error criteria.
\end{abstract}

Keywords: Time series, Lira exchange rate prediction, Financial markets, ARIMA models.

\section{INTRODUCTION}

Recently quantitative methods have turned into an urgent necessity to forecast financial markets and improve decisions and investments. Time series forecasting is considered as a very useful prediction method in which the previous observations are obtained and evaluated for the same constraint or phenomenon to construct a model which explains the basic relationship and then using the model to extrapolate the time series in the future.

The exchange rate is a relative price that measures the value of the local currency in terms of another currency. The exchange rate is one of the most effective variables in the financial environment for economic decision-makers and financial managers.

The importance of research stems from the fact that it is one of the leading researches of its kind to know the model and shape of exchange rate as one of the most important applications of modern time series forecasting.

At present, though there are various models of financial forecasting that can be obtained, but accurate forecasts of the rate of exchange is not an easy task and The utmost relevant research studies that used ARIMA models to predict exchange rates; [2] [4] [5] [6] [7] [9] [10]

This paper aims to adopt the best time series model using the Box-Jenkins methodology to build a prediction model at the rate of exchange of the Turkish lira VS. the US dollar. The statistical parameters have eliminated the RMSE and the absolute error rate of MAPE to measure the accuracy and quality of the prediction method. The research hypothesis states that the historical data behavior of the time series of the Turkish lira exchange rate follows the ARIMA of the autoregressive model type $P$. The time limit of the research represents the period from $1 / 2 / 2018$ to $30 / 6 / 2018$. The spatial limit represents the daily exchange 
rate of the Turkish lira. The structure of the research is divided into four main section : the first is presenting the abstract and the preface and the limits of research. The second section presents a theoretical basis for the research topic related to the theoretical structure of time series. The third section is presented to the application side of the research. The fourth section presents the most important results and conclusions reached through this research.

Related studies: The most relevant research studies that used ARIMA models to predict exchange rates (Bai 2015; C 2014; Gupta et al. 2016; Khashei, Ali, and Bijari 2015; Liu 2014; Pedram 2015; Rout et al 2014).

\section{LITERATURE}

The time series is defined as a set of random observations generated over time according to probabilistic laws, from a mathematical point of view. In other words, it is a set of observed values taken over time periods $[\mathrm{Z1}, \mathrm{Z2}, \ldots, \mathrm{Zn}]$, This set is the specific section of the sequence. There are also two trends in the analysis of the time series:

The first trend: Time Domain Analysis the Auto-Covariance Generating Function and the Autocorrelation Function are used in this direction, and are referred to as ACF and Partial Autocorrelation Function referred to as (PACF).

The time series is a linear compound with successive limits of independent random errors and matching distribution which was used in the present study $[3,8]$.

The second trend: Frequency Domain Analysis depends on the Spectrum Function and is called spectral analysis.

\subsection{Autocorrelation Function (ACF)}

The Autocorrelation function (ACF) is used to determine the appropriate model for the stable time series. The most important methods in determining the stability of the time series as well as the arithmetic mean and the constant variance if the coefficient of Autocorrelation between time series values at two points of time depends on the lag period $(k)$ between them and does not depend on the time $(t)$ itself, the series is stable [3] .

$$
\hat{\rho}_{k}=\frac{\hat{\gamma}_{k}}{\hat{\gamma}_{0}}=\frac{\sum_{t=1}^{n-k}\left(z_{t}-\bar{Z}\right)\left(z_{t+k}-\bar{Z}\right)}{\sum_{t=1}^{n}\left(z_{t}-\bar{Z}\right)^{2}} \ldots \ldots \text { (1) }
$$

Where the $\overline{\mathbf{Z}}$ Represents the sample mean for the time series $\mathbf{Z}_{t}$.

$$
\bar{z}=\frac{\sum_{t=1}^{n} Z_{t}}{n} \ldots . . .(2)
$$

\subsection{Partial Autocorrelation Function (PACF):}

The Partial Autocorrelation Function represented by (PACF) is used to determine the appropriate model for the stable time series. The partial Autocorrelation function is defined as the coefficients $\phi_{\boldsymbol{k} \boldsymbol{k}}$ of the

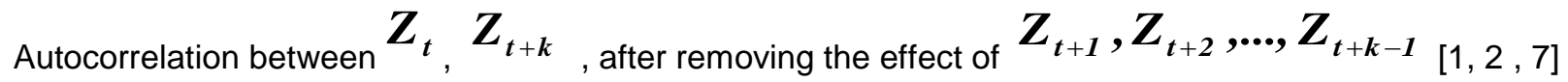
So:

$$
\operatorname{Corr}\left(Z_{t}, Z_{t+k} / Z_{t+1}, Z_{t+2}, \ldots, Z_{t+k-1}\right) \ldots(3)
$$

They are calculated according to the following formula: 


$$
\rho_{\mathrm{i}}=\phi_{\mathrm{k} 1} \rho_{\mathrm{i}-1}+\phi_{\mathrm{k} 2} \rho_{\mathrm{i}-2}+\cdots+\phi_{\mathrm{kk}} \rho_{\mathrm{i}-\mathrm{k}}, \boldsymbol{i}=\boldsymbol{1}, 2, \ldots, \boldsymbol{k}
$$

\subsection{Box-Jenkins Methodology}

The process of constructing the ARIMA model $(p, d, q)$ to represent and use time series data for prediction purposes is called the Box-Jenkins method. This method is one of the general methods for predicting different types of time series (stable and unstable, seasonal and non-seasonal) [1]

Because it does not assume that, a certain pattern exists in the string data prior to its application, as is the case with other prediction methods (eg, exponential boot methods) Rather, it begins with a pilot model determined by ACF and PACF functions. The parameters are then estimated based on time series observations to make forecast errors as low as possible, In this method, a number of indicators are adopted to make the researcher able to judge whether the model is appropriate or not The best predictor of the value of $\mathrm{Xt}$ in time $\mathrm{t}+\mathrm{L}$ which follows the general mixed model [3]

$\Phi_{\mathrm{p}}\left(\mathrm{B}^{\mathrm{s}}\right) \Phi_{\mathrm{p}}(\mathrm{B})(1-\mathrm{B})^{\mathrm{d}}\left(1-\mathrm{B}^{\mathrm{s}}\right)^{\mathrm{D}} \mathrm{X}_{\mathrm{t}}=\Theta_{\mathrm{Q}}\left(\mathrm{B}^{\mathrm{s}}\right) \theta_{\mathrm{q}}(\mathrm{B}) \mathrm{a}_{\mathrm{t}}$

Where (s) the length of the seasonal period is (conditional expectation) " where:

$$
\mathrm{X}^{\wedge} \mathrm{t}(\mathrm{L})=\mathrm{E}[\mathrm{Xt}+\mathrm{L} \mathrm{Xt}, \mathrm{Xt}-1, \ldots \ldots .]
$$

When the model (5) becomes stable, it can be rewritten in terms of random errors and as follows:

$X_{t}=\Psi(B) a_{t}=a_{t}+\Psi_{1} a_{t-1}+\Psi_{2} a_{t-2}+\ldots$

$$
=\Sigma \Psi_{\mathrm{J}} \mathrm{a}_{\mathrm{t}-\mathrm{J}}, \Psi_{0}=1
$$

Therefore, the future error prediction "forecast error" can be written as:

$\mathrm{e}_{\mathrm{t}}(\mathrm{L})=\mathrm{X}_{\mathrm{t}+\mathrm{L}}-\mathrm{X}_{\mathrm{t}}^{\wedge}(\mathrm{L})=\Sigma \Psi_{\mathrm{J}} \mathrm{a}_{\mathrm{t}+\mathrm{L}-\mathrm{J}}$

Since

$\mathrm{E}\left[\mathrm{e}_{\mathrm{t}}(\mathrm{L})\right]=0$

$$
\begin{gathered}
\mathrm{F} \operatorname{MSE}\left[\mathrm{X}_{\mathrm{t}}^{\wedge}(\mathrm{L})\right]=\mathrm{E}\left[\mathrm{X}_{\mathrm{t}}^{\wedge}(\mathrm{L})-\mathrm{X}_{\mathrm{t}+\mathrm{L}}\right]^{2}=\mathrm{E}\left[\mathrm{e}_{\mathrm{t}}^{2}(\mathrm{~L})\right] \\
=\sigma_{\mathrm{a}}^{2} \Sigma \Psi_{\mathrm{J}}^{2} \ldots \ldots \ldots \ldots
\end{gathered}
$$

\subsection{The stages of Building the Model According to the Box-Jenkins Method:}

In 1970, both Box and Jenkins proposed this method. Although the methodology of many of these stages was known before 1970, the Box-Jenkins first united these steps in the style identified by their names. The stages of the Box-Jenkins model are:[2, 3, 7, 8]

\subsubsection{Diagnosis}

The stage of diagnosis of the model is one of the important and difficult stages to reach the appropriate model. The main task of this stage is to diagnose and test the best model, which represents the time series of the ARMA $(p, q)$ or ARIMA $(p, d, q)$ models using the Autocorrelation and partial Autocorrelation factors. If the coefficients of the Autocorrelation function are decreasing exponentially and the partial Autocorrelation coefficients are cut after the (p) lag, the model is AR ( $p)$, and if the Autocorrelation coefficients decrease exponentially and the Autocorrelation coefficients are cut after the (q) lag, the model is MA (q). In the case of ARMA $(p, q)$, the Autocorrelation coefficients and the partial Autocorrelation coefficients are usually exponential.

Table (1) includes Summary of the different patterns of Autocorrelation and Partial Autocorrelation functions for the non-seasonal Models. 
Table (1) Diagnosis of the ARMA model

\begin{tabular}{|c|c|c|}
\hline $\begin{array}{c}\text { partial Autocorrelation } \\
\boldsymbol{P A C F}\end{array}$ & $\begin{array}{c}\text { Autocorrelation functions } \\
\boldsymbol{A C F}\end{array}$ & Model \\
\hline $\mathrm{AR}(\mathrm{p})$ & $\begin{array}{c}\text { Exponential Decaying } \\
\text { to 0 }\end{array}$ & Cuts off after lag $\mathrm{p}$ \\
\hline $\mathrm{MA}(\mathrm{q})$ & Cuts off after lag $\mathrm{q}$ & $\begin{array}{c}\text { Exponential Decaying } \\
\text { to 0 }\end{array}$ \\
\hline ARMA $(p, q)$ & $\begin{array}{c}\text { Exponential Decaying } \\
\text { to 0 }\end{array}$ & $\begin{array}{c}\text { Exponential Decaying } \\
\text { to 0 }\end{array}$ \\
\hline \multicolumn{2}{|c}{} \\
\hline
\end{tabular}

\subsubsection{Estimation}

There are several methods for estimating model parameters, some depending on the probability distribution of the time series. These methods are: Exact Maximum Likelihood, Approximate Maximum Likelihood, and methods that do not depend on the probability distribution of the time series, like the Least Square Method, also regularly efficient software is used efficiently for this purpose.

\subsubsection{Diagnostics}

At some stages, the estimation of the parameters of the model is the procedure for checking whether the model is appropriate or not. In addition, the residuals are white noise

\subsubsection{Prediction Accuracy}

To measure the accuracy of the results of the approved methods, the statistical criteria adopted were: RMSE And the absolute rate of error ratio MAPE under the following formulas $[2,4,8]$

$R M S E=\sqrt{\frac{\sum e_{t}^{2}}{n}}$

MAPE $=\frac{\sum\left|\frac{e_{t}}{X_{t}}\right|}{n} * 100$

\section{THE PRACTICAL PART}

Figure 1 represents the daily rate of exchange of the Turkish lira VS. the dollar for 150 days for the period from 1/2/2018 to 30/6/2018 (source data: the Wall Street website).

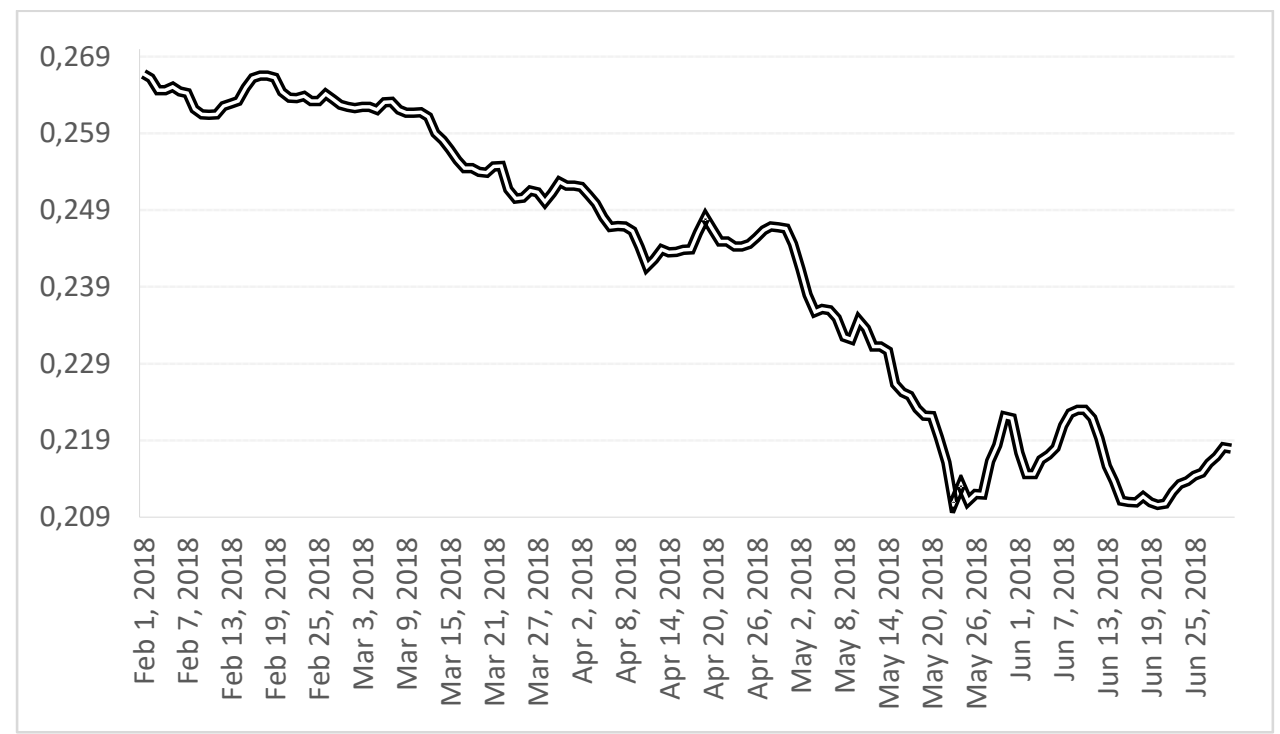

Figure (1) Series of exchange rate of the Turkish lira for the period 1/2/2018 - 30/6/2018.

Figure 2 illustrates the behavior of the Autocorrelation and Partial Autocorrelation coefficients of the time series in question calculated through SPSS program version 21. 

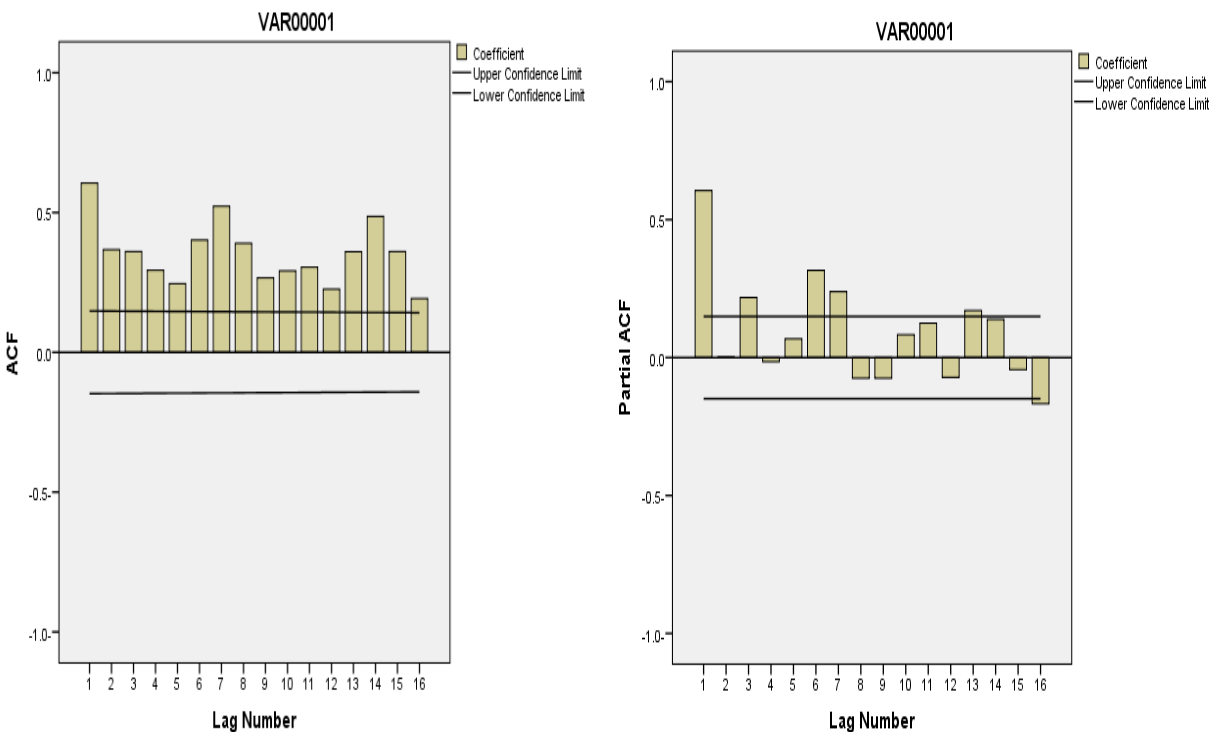

Figure (2) The behavior of the Autocorrelation and Partial Autocorrelation of the time series

\section{RESULTS}

Based on The behavior of ACF and PACF , the best ARIMA model for the time series under study is ARIMA $(1,0,0)$. The ARIMA model was estimated using SPSS version 21 , and the results of the model parameter estimated shown in Table (2) are revealed to be significant .

Table (2) Estimation of model parameters

\begin{tabular}{|c|l|l|l|l|}
\hline \multicolumn{2}{|c|}{ Estimation Parameters } & $\begin{array}{l}\text { Asympt. Std. } \\
\text { Err. }\end{array}$ & $\begin{array}{l}\text { Asympt. } \\
\mathbf{t}(\mathbf{1 7 8})\end{array}$ & p-value \\
\hline Constant & 1.407693 & 0.000667 & 2111.697 & 0.000 \\
\hline$\phi$ & 0.632879 & 0.58445 & 10.829 & 0.000 \\
\hline
\end{tabular}

Thus, the mathematical model is illustrated in equation (10).

$x_{t}=0.632879 x_{t-1}+\epsilon$

It is clear from figure (3) that the ACF and PACF of the residuals is a random behavior which indicate the value of the Ljung-Box test in Table (2) as significant for the sequence in Fig. 4. The estimated model is appropriate and the greatest.

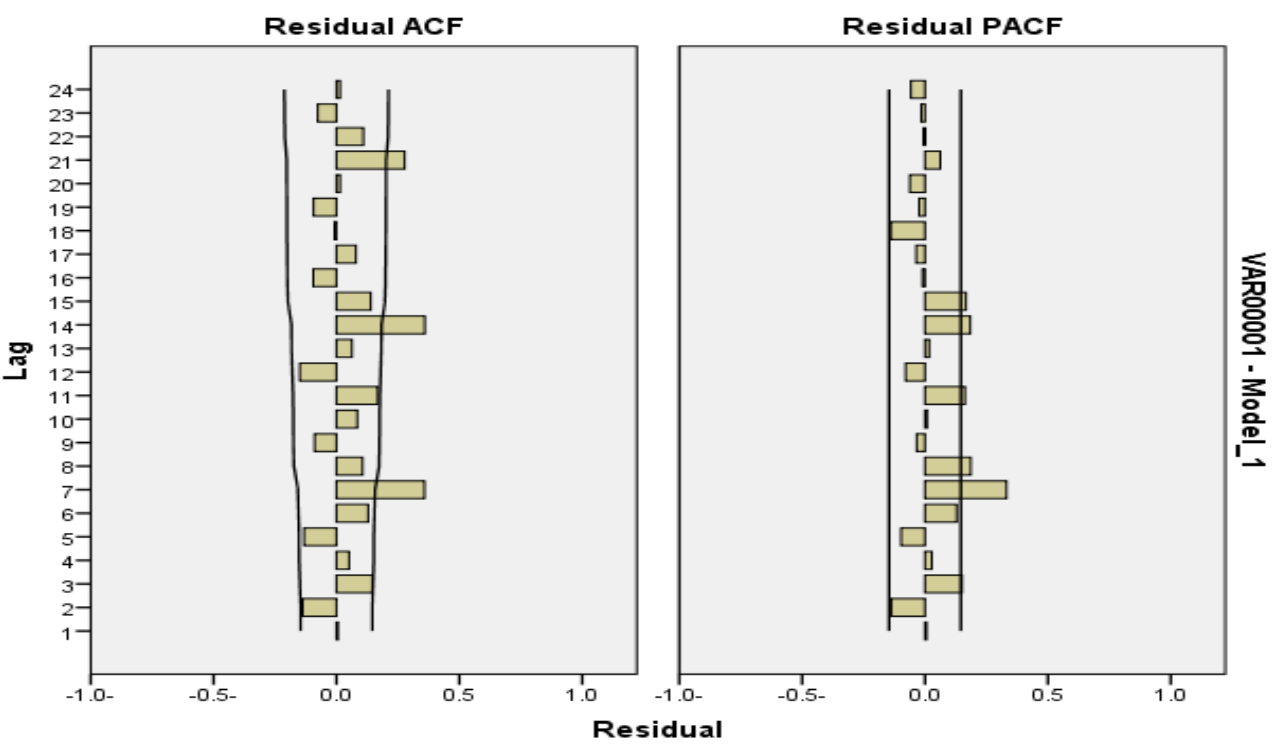

Figure (3): The behavior of the Autocorrelation and partial Autocorrelation of the residuals 
Table (3) Test outcomes of the model

\begin{tabular}{|c|c|c|c|c|c|c|c|c|}
\hline \multirow{2}{*}{ Model } & \multirow{2}{*}{$\begin{array}{l}\text { Number of } \\
\text { Predictors }\end{array}$} & \multicolumn{3}{|c|}{ Model Fit statistics } & \multicolumn{3}{|c|}{ Ljung-Box Q(18) } & \multirow{2}{*}{$\begin{array}{l}\text { Number of } \\
\text { Outliers }\end{array}$} \\
\hline & & $\begin{array}{l}\text { Stationary } \\
\text { R-squared }\end{array}$ & RMSE & MAPE & Statistics & DF & Sig. & \\
\hline Model_1 & 0 & .375 & .001 & .047 & 86.461 & 17 & .000 & 0 \\
\hline
\end{tabular}

Table (4) shows the results of the accuracy of the prediction method, the efficiency, quality and harmonization of the estimated model.

Table (4) Results of error accuracy criteria

\begin{tabular}{|l|l|l|}
\hline \multirow{2}{*}{ Fit Statistic } & RMSE & MAPE \\
\cline { 2 - 3 } & 0.001 & 0.047 \\
\hline
\end{tabular}

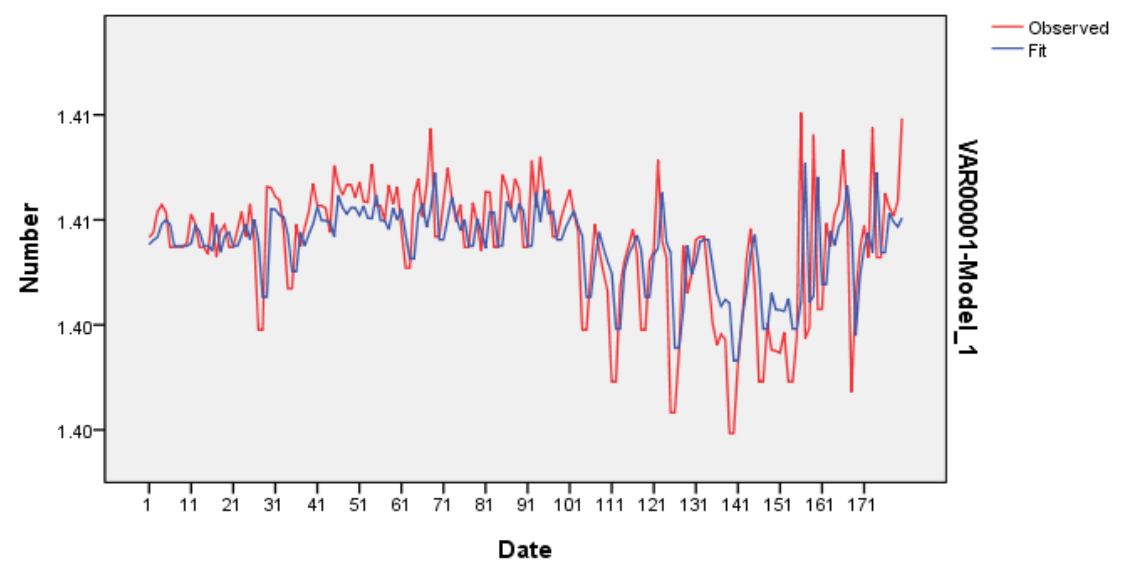

Figure (4) the curve fitting of time series

Table (5) shows the prediction values for the twelve-day period ahead of July 2018

Table (5) Prediction values for the future period

\begin{tabular}{|c|c||c|c}
\hline CaseNo. & Forecast & $\begin{array}{c}\text { Lower } \\
90.0000 \%\end{array}$ & $\begin{array}{c}\text { Upper } \\
90.0000 \%\end{array}$ \\
\hline 181 & 1.4092 & 1.4037 & 1.4146 \\
\hline 182 & 1.4086 & 1.4021 & 1.4151 \\
\hline 183 & 1.4083 & 1.4014 & 1.4151 \\
\hline 184 & 1.4081 & 1.4011 & 1.4151 \\
\hline 185 & 1.4079 & 1.4009 & 1.4150 \\
\hline 186 & 1.4078 & 1.4008 & 1.4149 \\
\hline 187 & 1.4078 & 1.4007 & 1.4149 \\
\hline 188 & 1.4078 & 1.4007 & 1.4148 \\
\hline 189 & 1.4077 & 1.4006 & 1.4148 \\
\hline 190 & 1.4077 & 1.4006 & 1.4148 \\
\hline 191 & 1.4077 & 1.4006 & 1.4148 \\
\hline 192 & 1.4077 & 1.4006 & 1.4148 \\
\hline
\end{tabular}

\section{CONCLUSIONS}

This paper shows that the best prediction model is ARIMA $(1,0,0)$, i.e. the Autoregressive model at the first degree and the error behavior in it was random. The results showed the significance of the parameters of the approved model. The results of the RMSE and MAPE error standards also demonstrated the efficiency and 
accuracy of the results of the approved prediction model.

\section{REFERENCE LIST}

[1 ] Ashour, M. A. H., Jamal, A., \& Helmi, R. A. A. (2018). Effectiveness of Artificial Neural Networks in Solving Financial Time Series. International Journal of Engineering \& Technology, 7(4.11), 99-105.

[2] Bai, Yaohui. 2015. "A Modified ARIMA Model Based on Extreme Value for Time Series Modelling." (Meic): 1197-1200.

[3] Box, George E P, Gwilym M Jenkins, Gregory C Reinsel, and Greta M Ljung. 2015. Time Series Analysis: Forecasting and Control. John Wiley \& Sons.

[4] C, Nwankwo Steve. 2014. "Autoregressive Integrated Moving Average ( ARIMA ) Model for Exchange Rate ( Naira to Dollar )." 3(4): 429-34.

[5] Gupta, Sanjeev, Sanjeev Gupta, Sachin Kashyap, and Sachin Kashyap. 2016. "Modelling Volatility and Forecasting of Exchange Rate of British Pound Sterling and Indian Rupee." Journal of Modelling in Management 11(2): 389-404.

[6] Khashei, Mehdi, Mohammad Ali, and Mehdi Bijari. 2015. "Comparison of Four Interval ARIMA-Base Time Series Methods for Exchange Rate Forecasting." (July): 21-34.

[7 ] Liu, J J. 2014. "A Multiscale Modeling Approach Incorporating ARIMA and Anns for Financial Market Volatility Forecasting." (June 2015).

[8 ] Moosa, I. 2016. Exchange Rate Forecasting: Techniques and Applications. Springer.

[9] Pedram, Mehdi. 2015. "The Effects of Economic Variables on Exchange Rate, Modeling and Forecasting: Case of Iran." 3(1): 13-23.

[10] Rout, Minakhi, Babita Majhi, Ritanjali Majhi, and Ganapati Panda. 2014. "Forecasting of Currency Exchange Rates Using an Adaptive ARMA Model with Differential Evolution Based Training." Journal of King Saud University-Computer and Information Sciences 26(1): 7-18. 